\title{
How does COVID-19 pandemic strength influence work fatigue? The mediating role of occupational calling
}

\author{
Jie Zhou ${ }^{1}$ \\ Accepted: 30 January 2022 \\ (c) The Author(s), under exclusive licence to Springer Science+Business Media, LLC, part of Springer Nature 2022
}

\begin{abstract}
Drawing on event system theory, this study explored the mechanism by which COVID-19 pandemic strength (including criticality, disruption, and novelty) influences work fatigue through the mediating role of occupational calling. A two-wave field study was conducted with 857 Chinese police officers using COVID-19 pandemic strength, occupational calling, and work fatigue questionnaires. The results showed that COVID-19 pandemic criticality had a positive effect on work fatigue and occupational calling, and that occupational calling mediated the direct link between COVID-19 pandemic criticality and work fatigue. Additionally, the first and second stages of the mediating effect were jointly moderated by COVID-19 pandemic disruption and novelty. When COVID-19 pandemic disruption and novelty were high, the positive relationship between COVID-19 pandemic criticality and occupational calling, and the mediating role of occupational calling, were stronger. The negative relationship between occupational calling and work fatigue was strengthened when COVID-19 pandemic disruption was high and novelty was low.
\end{abstract}

Keywords COVID-19 pandemic strength $\cdot$ Event system theory $\cdot$ Occupational calling $\cdot$ Work fatigue

\section{Introduction}

The coronavirus disease 2019 (COVID-19) pandemic has widely and deeply affected human lives and work since 2020 (Liu et al., 2021; Zhu et al., 2020). According to the World Health Organization (2021), as of December 25, 2021, over 200 million people had been infected and 5 million people had died worldwide. The high risk of infection, factory shutdowns, unemployment, and a chaotic social order have unprecedentedly increased the workload and stress of police officers, thus creating immense physical and psychological challenges for them. Accordingly, research on work fatigue caused by the occupational characteristics of police has increased (Stogner et al., 2020). In a sample of 5,467 police officers in a significant sub-central city of Hubei Province in China, more than $70 \%$ experienced work stress and fatigue, and $21.6 \%$ had difficulties in adaptation (Zhu et al., 2020). Furthermore, $50 \%$ of Indian police officers reported mental

Jie Zhou

jojozhou1022@163.com

1 Department of Police Management, Sichuan Police College, No. 186 Longtouguan road, Jiangyang district, Luzhou, Sichuan province, China disturbances, and 32.4\% reported work stress after the pandemic (Khadse et al., 2020). Work fatigue among police officers remains an important theoretical and practical issue (Zhou et al., 2020), and has received considerable attention from researchers and managers.

In the past, numerous studies have explored the effects of individual psychological and external environmental factors on work fatigue. These include stressors (Stogner et al., 2020), passive emotions (Ashforth \& Schinoff, 2016), depression and anxiety (Teng et al., 2020), insomnia (Fekedulegn et al., 2017), and demanding working conditions and negative events (Bacharach \& Bamberger, 2007). However, the effects of external event attributes on police officers' work fatigue remains overlooked, particularly concerning COVID-19 pandemic. Zhou et al. (2020) explored the effect of COVID-19 pandemic disruption on the link between occupational calling and work fatigue. However, they did not examine the joint interactive effect of various characteristics of COVID-19 pandemic strength on work fatigue. In contrast to previous pandemics, COVID-19 has the fastest transmission speed, greatest difficulty in prevention and control, and widest transmission range. These characteristics correspond with the attributes of event criticality, disruption, and novelty (Liu et al., 2020); and, drawing upon Event 
System Theory (EST), COVID-19 pandemic strength will influence police officers' work fatigue (Gross et al., 2011).

Moreover, the mechanism underlying the link between COVID-19 pandemic attributes and work fatigue must be further investigated. Recent research demonstrates that COVID-19 pandemic strength is associated with emotional exhaustion, and that high prosocial motivation strengthens this link (Caldas et al., 2021; Zhu et al., 2021). Prosocial motivation is a typical occupational calling attribute (Praskova et al., 2015; Zhang et al., 2015). Police officers often experience a high sense of occupational calling because of the high social responsibility related to their job (Zhou et al., 2020). However, they also experience work fatigue in a dynamic and stressful environment (Fekedulegn et al., 2017). The COVID-19 pandemic criticality has increased police officers' awareness of their occupational calling and responsibility, which may reduce their work fatigue (Zhou et al., 2020). Thus, the link between COVID-19 pandemic criticality and work fatigue may be mediated by occupational calling.

Hence, drawing upon EST, this study investigated the mechanism of COVID-19 pandemic criticality on Chinese police officers' work fatigue through occupational calling, within the boundary conditions of COVID-19 pandemic disruption and novelty. This contributes to elucidating the mechanism of how and when attributes of COVID-19 pandemic strength affect work fatigue, thus helping organizations meet frontline workers' psychological needs and helping them reduce their work fatigue. The research model is illustrated in Fig. 1.

\section{Theory and Hypothesis Development}

\section{EST}

EST considers that life and work events dynamically impact individuals' psychological status and behaviors via the synergistic effect of event time, space, and strength (Morgeson et al., 2015). Specifically, a longer duration, wider range, and higher event strength increases the impact on individuals.
The COVID-19 pandemic has proliferated worldwide and its strength varies. The different attributes of COVID-19 pandemic strength have influenced individuals' psychological and behavioral responses (Liu et al., 2020). Among these attributes, criticality refers to the impact of an entity's goals. Stronger criticality requires an entity to allocate more attention and resources to cope with the event. Disruption reflects changes in an entity's normal coping strategies. Stronger disruption requires entities to adjust their psychological and behavioral patterns. Novelty is defined as how much the event varies from previous ones, with stronger novelty requiring a higher level of attention to change psychological and behavioral responses.

EST has been widely used in the fields of organizational behavior (Chen et al., 2021; Morgeson \& DeRue, 2006), health psychology (Zhou et al., 2020), and social psychology (Bacharach \& Bamberger, 2007). As the critical, disruptive, and novel COVID-19 pandemic has significantly influenced police officers' work and life, we believe that EST is appropriate for examining the mechanism of the three attributes of COVID-19 pandemic strength on police officers' work fatigue. Furthermore, a study of Chinese civilians by Zheng (2020) demonstrated that the significance of COVID-19 pandemic criticality was more profound than its disruption and novelty. Hence, this study investigated the link between COVID-19 pandemic criticality and work fatigue through occupational calling and regarded disruption and novelty as situational variables.

\section{Link Between COVID-19 Pandemic Criticality and Work Fatigue}

Work fatigue is defined as "extreme tiredness and reduced functional capacity that is experienced during and at the end of the workday" (Frone \& Tidwell, 2015, p. 274). It has a pervasive influence on human work and life and constitutes a major threat to health and well-being in the modern workplace. Among the U.S. workforce, 38\% reported work fatigue (Ricci et al., 2007). The condition is even worse for police officers (Burki, 2020), with $46 \%$ reporting chronic

Fig. 1 The research model

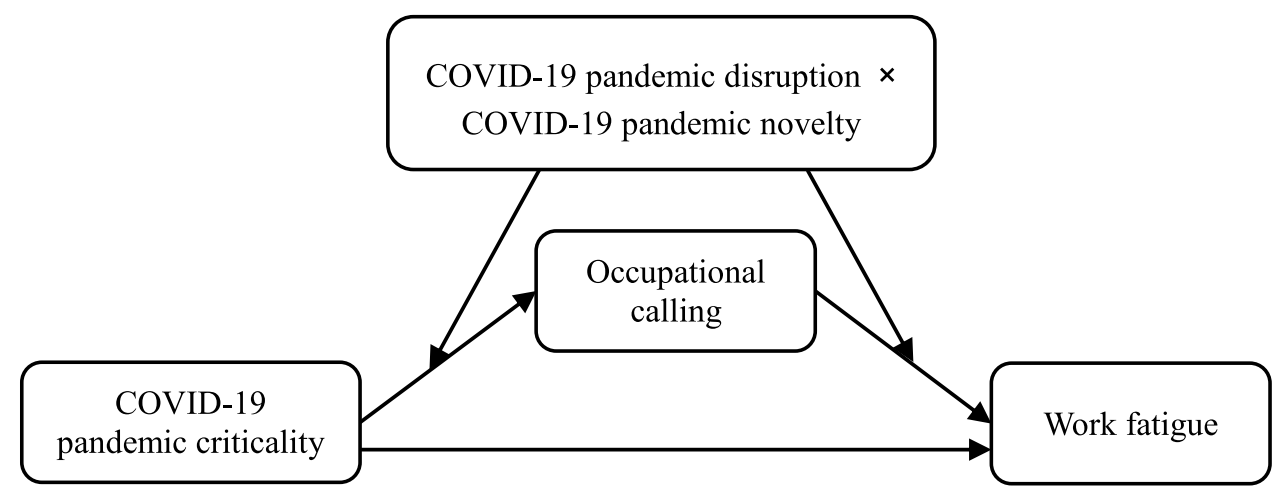


fatigue in the U.S. (Fekedulegn et al., 2017), as they are the first responders to prolonged exposure to stressors in emergencies, terrorist attacks, natural disasters, and traumatic events (Vila, 2006). Such events directly affect individuals' work status, which is especially true for the COVID19 pandemic (Drew \& Martin, 2020). According to Teng et al. (2020), among 2,614 Chinese frontline workers, 73.7\% (including police officers) experienced work fatigue during the COVID-19 pandemic.

The primary job of police officers is to maintain public order and fight crime; however, the COVID-19 pandemic has disrupted police officers' goals, and pandemic prevention and control have taken priority in their daily work. In this context, police officers must undertake more responsibilities, actively mobilize resources, and allocate more attention to cope with the pandemic. According to statistics from the Ministry of Public Security in China (2020), nearly 120,000 police officers in Hubei province participated in COVID-19 pandemic prevention and control efforts, and over 40,000 police officers in Wuhan were on duty in hospitals and at the entrance and exit of cities for weeks. They subsequently experienced stress, anxiety, insomnia, and depression (Teng et al., 2020). Studies have confirmed that police officers' work involves inherent physical and psychological dangers, and that the above-mentioned symptoms could result in higher work fatigue during the COVID-19 pandemic (Frone \& Tidwell, 2015; Rose et al., 2017; Thorsteinsson et al., 2014). Hence, we hypothesized the following:

Hypothesis 1: COVID-19 pandemic criticality is positively related to work fatigue.

Mediating Effect of Occupational Calling Occupational calling refers to a strong sense of meaning and passion experienced by individuals in specific fields, on a continuum from weak to strong (Dobrow \& Tosti-Kharas, 2011). Compared with other general occupations, police officers predominantly experience a stronger sense of occupational calling because of their occupational role and social responsibility (Bullough \& Hall-Kenyon, 2011; Michaelson \& TostiKharas, 2019). This is bolstered when their country and people need them. Based on EST, the availability and completeness of event information depend on individuals' spatial distance perceptions (Morgeson et al., 2015). Specifically, when an event is close to individuals, they will obtain more accurate and refined information, which further affects their perceptions. Police officers participated in pandemic prevention and control and were more likely to recognize the criticality of the pandemic. In this context, the pandemic criticality and citizens' fear and anxiety could mentally reinforce police officers' occupational oath, thus encouraging them to satisfy their country's needs, and increasing their occupational calling (Zhang et al., 2015; Zhao \& Zheng, 2013). Moreover, the higher the criticality and danger police officers perceive, the more their occupational calling is bolstered. This is especially true in the Chinese collective culture, as police officers' jobs match the needs of the country and of broader society well (Deng \& Chen, 2019). Therefore, we hypothesized the following:

Hypothesis 2: COVID-19 pandemic criticality is positively related to occupational calling.

Furthermore, research refers to occupational calling as a type of job-related resource (Creed et al., 2014; Lysova et al., 2019). Individuals with a stronger sense of occupational calling have more resources to cope with work demands, which improves their satisfaction, well-being (Duffy et al., 2014), and autonomous work motivations (Lee et al., 2018). Moreover, it reduces their work fatigue and job burnout (Wright \& Cropanzano, 2000; Dik \& Duffy, 2009; Zhou et al., 2020). Contrastingly, individuals with a weak sense of occupational calling have fewer internal resources to cope with the stressors caused by a high workload (Duffy et al., 2012) and involuntary overtime (Beckers et al., 2008). This subsequently leads to resource loss and work fatigue (Burke, 1994; Clinton et al., 2017; Frone \& Tidwell, 2015). This reasoning led us to expect a negative impact of occupational calling on work fatigue. Accordingly, based on our arguments regarding Hypotheses 1 and 2, we proposed the following:

Hypothesis 3: Occupational calling mediates the link between COVID-19 pandemic criticality and work fatigue.

Joint Interactive Impact of COVID-19 Pandemic Disruption and Novelty An event, as a situational factor, affects an individual's life and work (Haney-Loehlein et al., 2015). EST proposes that the attributes of event strength can be recognized as both independent variables and situational variables (Morgeson et al., 2015). Scholars have revealed that the three attributes of COVID-19 pandemic strength have different influences on emotional exhaustion (Liu et al., 2020), role overload, and work fatigue (Zhou et al., 2020). Therefore, the COVID-19 pandemic disruption and novelty as macro contextual factors may jointly moderate the link between occupational calling and work fatigue, which should be further examined (Zhou et al., 2020).

Thus, based on EST, we firstly propose that the link between COVID-19 pandemic criticality and occupational calling will be stronger under conditions of high COVID19 pandemic disruption and novelty. Specifically, as police officers are the first responder of pandemic prevention and control, their job goals are disrupted severely. Thus, they 
will perceive a higher disruption and novelty of the pandemic than the public and experience a higher risk (Trope \& Liberman, 2010). Under such circumstances, police officers may experience a greater sense of work meaning and value, a stronger motivation, and more prosocial behaviors to fight the pandemic (Zheng, 2020). Therefore, the relationship between COVID-19 pandemic criticality and occupational calling will be stronger. Conversely, under the condition of high (low) disruption and low (high) novelty, the external stimulus on police officers' perception and behavior will be weaker than when the disruption and novelty are both high. Thus, their joint impact on the link between event criticality and occupational calling will be weaker. Moreover, when the pandemic disruption and novelty are both low, a weak situational stimulus (Cooper \& Withey, 2009; Mischel, 1977) is less likely to arouse and change police officers' psychological and behavioral patterns regarding the pandemic, even under the condition of high criticality. Therefore, we hypothesized the following:

Hypothesis 4: COVID-19 pandemic disruption and novelty jointly moderate the positive link between COVID-19 pandemic criticality and occupational calling, such that higher disruption and novelty strengthen this link.

Second, we propose that the negative link between occupational calling and work fatigue will be stronger under conditions of high COVID-19 pandemic disruption and low novelty. Specifically, when police officers experience higher disruption and lower novelty, they can strengthen their work meaning and social expectations, and focus on handling jobs based on previous experience, thereby enhancing their confidence, work passion, and vigor to fight the pandemic, and reducing their work fatigue (Deng \& Chen, 2019; Frone \& Tidwell, 2015; Zhou et al., 2020). Furthermore, a survey demonstrated that Chinese citizens perceived that COVID19 pandemic disruption more profoundly impacted their life and work than novelty did (Zheng, 2020). Similarly, when the COVID-19 pandemic is minimally disruptive and highly novel, despite attracting more attention than previous emergencies, individuals' lives and work, the social order, police officers' job goals, and law enforcement activities are less disrupted. Therefore, under such conditions, the negative impact of occupational calling on work fatigue will be strengthened. Conversely, the joint interactive effect will be weaker than when pandemic disruption and novelty are high. Contrastingly, according to the strong situation hypothesis (Cooper \& Withey, 2009; Mischel, 1977), when the COVID19 pandemic is highly disruptive and novel, an extremely strong external stimulus will mask the positive impact of occupational calling on reducing work fatigue. Moreover, when pandemic disruption and novelty are lower, a weak situational stimulus is insufficient to strengthen the link between occupational calling and work fatigue. Thus, we hypothesized the following:

Hypothesis 5: COVID-19 pandemic disruption and novelty jointly moderate the link between occupational calling and work fatigue, such that when disruption is high and novelty is low, the link is stronger.

As argued in Hypotheses 3, 4, and 5, COVID-19 pandemic disruption and novelty may jointly moderate the first and second stages of the mediating effect. As pandemic disruption and novelty increase, the criticality of the pandemic will fuel occupational calling and reduce work fatigue under a strong external stimulus. That is, the mediating role of occupational calling between pandemic criticality and work fatigue will be stronger. Therefore, we hypothesized the following:

Hypothesis 6: COVID-19 pandemic disruption and novelty have a joint moderating effect on the link between pandemic criticality and work fatigue through occupational calling, such that when disruption and novelty are high, the indirect link is stronger.

\section{Methods}

\section{Participants and Procedure}

A two-wave field design and cluster sampling method were used in this study. We collected data at two time points in a police training program (from October to December 2020) using a field confidential questionnaire to minimize potential common method deviation. Notably, all police officers in this training program were under closed management because of the isolation policy in China at the beginning of the COVID19 pandemic. Before data collection, the participants were gathered at an auditorium before having a class and were told that the survey was unrelated to their performance appraisal and promotion. Additionally, in order to reduce the sample loss caused by questionnaire mismatches of two time points as much as possible, each police officer was required to write their unique police number on the questionnaire cover. And no one knew what the exact identity of their police number represented and this was confidential for others. When they consented to participate in the survey, we distributed the questionnaires. First, we collected demographic information, COVID-19 pandemic strength characteristics, and organizational support. At the second time point (one month later), occupational calling and work fatigue were measured using the same procedure as in time point 1 .

A total of 919 questionnaires were distributed and returned. Two researchers then checked and matched the 
data collected at times 1 and 2 according to the police numbers on the questionnaire cover. Sixty-two invalid questionnaires were excluded for remarkable consistency or missing data, and 857 questionnaires were finally obtained, thus yielding a valid response rate of $93.25 \%$. Of the participants, $80.4 \%$ (689) were men and $19.6 \%$ (168) were women; $56.8 \%$ (487) were aged 30 years and below, $34.2 \%$ (293) were aged $31-40$ years, and $9.0 \%$ (77) were 41 years and above. Regarding tenure, $36.9 \%$ (316) of the police officers had less than 1 year; $23.3 \%$ (200) had 2-5 years; $18.3 \%$ (157) had $6-10$ years; and $21.5 \%$ (184) had 11 years or more.

\section{Measures}

All scales in this study were revised from existing scales. Each item was rated on a 5-point Likert scale, and Cronbach's $\alpha$ is presented in Table 2. All the scales showed good reliability in this study.

\section{COVID-19 Pandemic Strength}

The COVID-19 pandemic strength scale was revised from the event strength scale (Morgeson \& DeRue, 2006) which was translated into Chinese by Liu and Liu (2017). This scale includes 11 items with three dimensions (criticality, disruption, and novelty) and has been widely used in the Chinese context and demonstrates good reliability (Liu et al., 2021; Zheng, 2020). In this study, all items are presented in Table 2 and rated on a 5-point Likert scale ( $1=$ strongly disagree, $5=$ strongly agree). Notably, the item, "The COVID19 pandemic disrupts my ability to get my work done" in the dimension of disruption was deleted in this study for two reasons. First, the factor loading of it was 0.44 (far less than 0.50). We thus interviewed 4 professors who majored in organizational behavior and psychology and 11 police officers who had participated in pandemic prevention and control. They all agreed that although the COVID-19 pandemic disrupted police officers' normal work course, their ability to complete their work remained relatively stable, and was not seriously influenced by the pandemic disruption. Hence, they suggested that we delete this item and re-analyze it. Second, in the context of Chinese collectivist culture, police officers were the first responders to pandemic prevention and control. Therefore, they had to complete law enforcement activities and participate in other non-policing activities during the pandemic, which actually may improve their ability to complete their work.

\section{Occupational Calling}

We used the 2-item brief calling presence scale developed by Dik et al. (2012), with a Cronbach's $\alpha$ of 0.79. Zhu et al. (2021) and Yang and Chen (2020) used the same items to measure Chinese nurses' occupational calling at the beginning of the COVID-19 pandemic, and the Cronbach's $\alpha$ in their studies was 0.90 and 0.89 , respectively. This indicates good reliability for the Chinese population. In this study, we substituted "be a police officer" for "a particular kind of work" in the first item.

\section{Work Fatigue}

In this study, we adopted three items from each dimension with a higher factor loading from an 18-item work fatigue scale developed by Frone and Tidwell (2015). The three dimensions were physical, mental, and emotional fatigue, with six items in each dimension. A previous study showed good reliability and validity for police officers in China (Zhou et al., 2020).

\section{Organizational Support}

The three highest-loading items of a perceived organizational support scale by Eisenberger et al., (1986) were used. This scale has been widely used in the Chinese context and has been adapted to the Chinese population (Qiu et al., 2020; Teng et al., 2020; Zhou et al., 2020).

\section{Control Variables}

According to various studies, demographic variables (Rose et al., 2017) and organizational support (Qiu et al., 2020; Teng et al., 2020) can affect work fatigue. Thus, sex (female $=0$, male $=1$ ), age, police tenure, and organizational support were controlled in this study.

\section{Data Analysis}

In this study, SPSS 25.0 was utilized for descriptive statistics analysis. Model 72 in the bootstrap inspection of the PROCESS macro V2.13.2 (Hayes, 2013) was utilized to test a jointly moderated mediating model. In this model, two moderators (W= COVID-19 pandemic disruption; $\mathrm{Z}=$ COVID19 pandemic novelty) synergistically moderated the first and second paths of the mediating effect simultaneously. Moreover, Amos 24.0 was utilized to conduct CFA.

\section{Results}

\section{Preliminary Analysis}

\section{Common Method Deviation and Discriminant Validity Tests}

This study collected self-reported data; hence, we used partial correlation analysis to test for common method deviation (Podsakoff et al., 2003). The partial correlation analysis 
Table 1 Means, standard deviations and correlation coefficients of variables

\begin{tabular}{|c|c|c|c|c|c|c|c|}
\hline Variables & M & SD & 1 & 2 & 3 & 4 & 5 \\
\hline 1. COVID-19 pandemic criticality & 4.13 & 0.71 & 0.77 & & & & \\
\hline 2. COVID-19 pandemic disruption & 3.67 & 0.70 & $0.24^{* * *}\left(0.24^{* * *}\right)$ & 0.73 & & & \\
\hline 3. COVID-19 pandemic novelty & 3.81 & 0.76 & $0.45^{* * *}\left(0.40^{* * *}\right)$ & $0.13^{* * *}\left(0.12^{* * *}\right)$ & 0.71 & & \\
\hline 4. Occupational calling & 3.68 & 1.00 & $0.21^{* * *}\left(0.13^{* * *}\right)$ & $0.09^{* * *}\left(0.09^{* *}\right)$ & $0.33^{* * *}\left(0.28^{* * *}\right)$ & 0.85 & \\
\hline 5. Work fatigue & 3.29 & 0.88 & $0.04\left(0.11^{* *}\right)$ & $0.10^{* * *}\left(0.11^{* * *}\right)$ & $-0.15^{* *}\left(-0.09^{* * *}\right)$ & $-0.22^{* * *}\left(-0.17^{* * *}\right)$ & 0.84 \\
\hline 6. Organizational support & 3.49 & 0.96 & $0.29^{* * *}$ & 0.03 & $0.26^{* * *}$ & $0.31^{* * * *}$ & $-0.23^{* * *}$ \\
\hline
\end{tabular}

Table 2 The statement, loading, and Cronbach's $\alpha$ of all measures

\begin{tabular}{|c|c|c|c|c|}
\hline Variables & Items & Loading & $\mathrm{CR}$ & AVE \\
\hline \multirow[t]{13}{*}{ COVID-19 pandemic strength $(\alpha=0.78)$} & Factor 1: COVID-19 pandemic criticality $(\alpha=0.78)$ & 0.88 & 0.81 & 0.60 \\
\hline & 1. The COVID-19 pandemic is of priority to me. & & & \\
\hline & 2. The COVID-19 pandemic is critical for the long-term success of me. & 0.49 & & \\
\hline & 3. The COVID-19 pandemic is an important event for me. & 0.89 & & \\
\hline & Factor 2: COVID-19 pandemic novelty $(\alpha=0.76)$ & 0.52 & 0.79 & 0.50 \\
\hline & 4. I had a clear, known way to respond to the COVID-19 pandemic. (R) & & & \\
\hline & $\begin{array}{l}\text { 5. I had an understandable sequence of steps that can be followed in respond- } \\
\text { ing to the COVID-19 pandemic. (R) }\end{array}$ & 0.58 & & \\
\hline & $\begin{array}{l}\text { 6. I can rely on established procedures and practices in responding to the } \\
\text { COVID-19 pandemic. (R) }\end{array}$ & 0.84 & & \\
\hline & $\begin{array}{l}\text { 7. I had rules, procedures, or guidelines to follow when the COVID-19 pan- } \\
\text { demic occurred. (R) }\end{array}$ & 0.83 & & \\
\hline & Factor 3: COVID-19 pandemic disruption $(\alpha=0.79)$ & 0.56 & 0.76 & 0.53 \\
\hline & 8. The COVID-19 pandemic causes me to stop and think about how to respond. & & & \\
\hline & 9. The COVID-19 pandemic alters my normal way of responding. & 0.82 & & \\
\hline & 10. The COVID-19 pandemic requires me to change the way it does my work. & 0.77 & & \\
\hline \multirow[t]{2}{*}{ Occupational calling ( $\alpha=0.84)$} & 1. I have a calling to be a police officer. & 0.91 & 0.84 & 0.73 \\
\hline & 2. I have a good understanding of my calling as it applies to my career. & 0.79 & & \\
\hline \multirow[t]{13}{*}{ Work fatigue $(\alpha=0.94)$} & After the COVID-19 pandemic breakout, how often did you: & 0.81 & 0.86 & 0.67 \\
\hline & Factor 1: Physical fatigue $(\alpha=0.86)$ & & & \\
\hline & 1. Feel physically exhausted at the end of the workday? & & & \\
\hline & 2. Feel physically worn out at the end of the workday? & 0.70 & & \\
\hline & 3. Feel physically drained at the end of the workday? & 0.95 & & \\
\hline & Factor 2: Mental fatigue $(\alpha=0.89)$ & 0.89 & 0.89 & 0.73 \\
\hline & 4. Feel mentally exhausted at the end of the workday? & & & \\
\hline & 5. Feel mentally worn out at the end of the workday? & 0.77 & & \\
\hline & 6. Feel mentally drained at the end of the workday? & 0.90 & & \\
\hline & Factor 3: Emotional fatigue $(\alpha=0.88)$ & 0.78 & 0.88 & 0.71 \\
\hline & $\begin{array}{l}\text { 7. Have difficulty showing and dealing with emotions at the end of the work- } \\
\text { day? }\end{array}$ & & & \\
\hline & 8. Feel emotionally worn out at the end of the workday? & 0.84 & & \\
\hline & 9. Feel emotionally drained at the end of the workday? & 0.91 & & \\
\hline \multirow[t]{3}{*}{ Organizational support $(\alpha=0.88)$} & 1. The organization really cares about my well-being. & 0.79 & 0.88 & 0.70 \\
\hline & 2. The organization shows very little concern for me. (R) & 0.86 & & \\
\hline & 3. The organization cares about my opinions. & 0.86 & & \\
\hline
\end{tabular}


results (see Table 1) showed that organizational support was significantly and positively correlated with COVID-19 pandemic criticality, novelty, and occupational calling; however, it was negatively correlated with work fatigue. The coefficients ranged from -0.23 to 0.31 . After controlling for organizational support, the partial correlations between the other variables were significant. The partial coefficients ranged from -0.17 to 0.40 . Therefore, this research had some common method deviation, but it was not serious.

Furthermore, as shown in Table 2, the CR and AVE values for occupational calling, COVID-19 pandemic criticality, COVID-19 pandemic disruption, COVID-19 pandemic novelty, organizational support, and three dimensions of work fatigue fit the standard ( $\mathrm{CR} \geq 0.7, \mathrm{AVE} \geq 0.5$ ). Moreover, according to Fornell and Larcker (1981), if the square root value of AVE is greater than the correlation coefficients between this variable and all others, the discriminant validity fits the standard. As shown in bold in Table 1, the AVE square root value of each variable fit this standard. Additionally, CFA revealed that the research model fit was acceptable $\left(\chi^{2} / \mathrm{df}=5.43, \mathrm{RMSEA}=0.07, \mathrm{GFI}=0.90, \mathrm{CFI}=0.92\right)$ and better than that of other alternative models. All these indices indicated that the discriminant validity of all the variables was acceptable.

\section{Descriptive Statistics Analysis}

Table 1 shows the means, standard deviations, and correlation coefficients for all variables. The results indicated that COVID-19 pandemic criticality was significantly and positively correlated with disruption, novelty, and occupational calling, but non-significantly correlated with work fatigue. The coefficients ranged from -0.22 to 0.45 .

\section{Hypothesis Testing}

All variables in the regression analysis were standardized. A roadmap of the model is shown in Fig. 2. As shown in Models 1 and 2 of Table 3, COVID-19 pandemic criticality had a significant and positive effect on work fatigue $(\beta=0.12, p<0.01)$ and occupational calling $(\beta=0.12$, $p<0.01)$, thereby supporting Hypotheses 1 and 2. Moreover, COVID-19 pandemic criticality significantly and positively influenced work fatigue $(\beta=0.14, p<0.001)$, and occupational calling significantly and negatively influenced work fatigue $(\beta=-0.19, p<0.001)$ after adding occupational calling as a mediator (see Model 3 in Table 3 ). This indicates that occupational calling mediated the link between COVID19 pandemic criticality and work fatigue, thus supporting Hypothesis 3.

Furthermore, Model 4 in Table 3 indicates that the synergistic interactive effect of COVID-19 pandemic criticality, disruption, and novelty on occupational calling was significant and positive $(\beta=0.10, p<0.05)$. Figure 3 indicates that the positive relationship between COVID-19 pandemic criticality and occupational calling was stronger under the condition of high COVID-19 pandemic disruption and novelty ( slope $_{\text {high-high }}=0.26, p<0.001$ ) than under high disruption and low novelty ( slope $_{\text {high-low }}=-0.10, p>0.5$ ), low disruption and novelty (slope low-high $=-0.02, p>0.5$ ), and low disruption and novelty (slope low-low $=-0.01, p>0.5$ ). Thus, Hypothesis 4 was supported. The significance of the simple slope difference test is shown on the left of Table 4 .

Moreover, as shown in Model 5 of Table 3, the synergetic interactive effect of occupational calling, COVID19 pandemic disruption, and novelty on work fatigue was significant and positive $(\beta=0.08, p<0.05)$. Figure 4 illustrates that the negative relationship between occupational calling and work fatigue was stronger under the condition of high COVID-19 pandemic disruption and low novelty (slope $\left._{\text {high-low }}=-0.28, p<0.001\right)$ than under high disruption and low novelty (slope low-high $=-0.24, p<0.001$ ), high disruption and high novelty (slope high-high $=-0.16, p>0.05$ ), and under low disruption and low novelty ( slope $_{\text {low-low }}=-0.05$, $p>0.5$ ), supporting Hypothesis 5. The significance of the simple slope difference test is shown in the right part of Table 4.

Finally, as shown in Table 5, only when COVID-19 pandemic disruption and novelty were high, the $95 \%$ confidence interval of the mediating effect of occupational calling excluded zero $(-0.082,-0.002)$. This indicates that the
Fig. 2 The roadmap of the effect of COVID-19 pandemic criticality on work fatigue

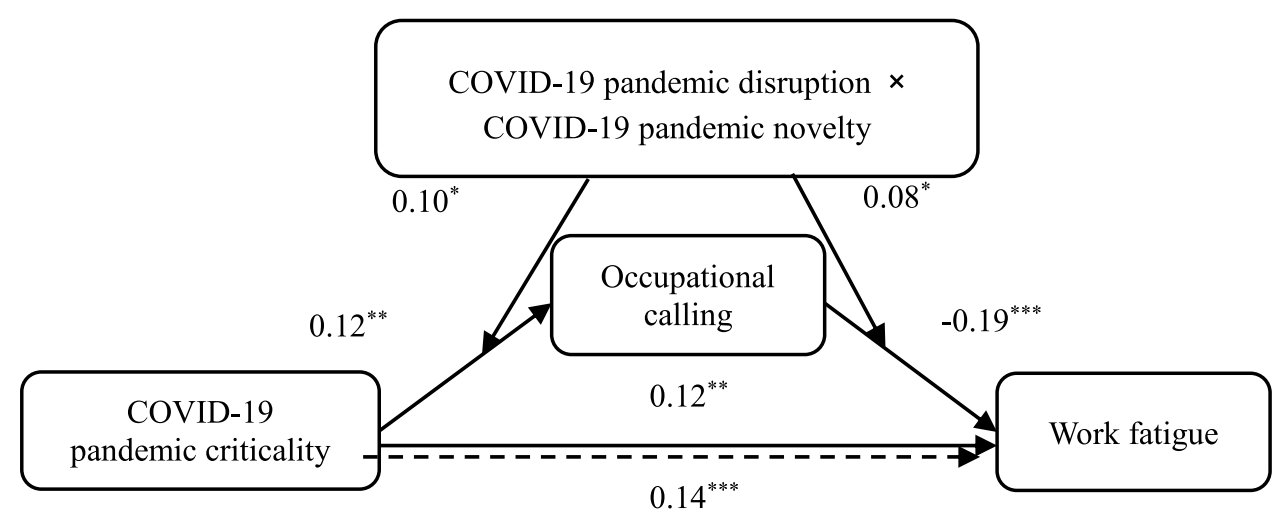


Table 3 Hierarchical linear regression results of the jointly moderated mediating effect

\begin{tabular}{|c|c|c|c|c|c|}
\hline \multirow[t]{2}{*}{ Variables } & Work fatigue & $\begin{array}{l}\text { Occu- } \\
\text { pational } \\
\text { calling }\end{array}$ & Work fatigue & $\begin{array}{l}\text { Occu- } \\
\text { pational } \\
\text { calling }\end{array}$ & Work fatigue \\
\hline & Model 1 & Model 2 & Model 3 & Model 4 & Model 5 \\
\hline Sex & 0.32 & $0.10^{* *}$ & 0.05 & $0.08^{*}$ & 0.03 \\
\hline Age & 0.10 & $-0.12^{*}$ & -0.01 & $-0.15^{* *}$ & 0.01 \\
\hline Police tenure & 0.04 & $-0.10^{*}$ & 0.02 & -0.01 & -0.02 \\
\hline Organizational support & $-0.27^{* * *}$ & $0.32^{* * *}$ & $-0.21^{* * *}$ & $0.27^{* * *}$ & $-0.20^{* * *}$ \\
\hline COVID-19 pandemic criticality & $0.12^{* *}$ & $0.12^{* *}$ & $0.14^{* * *}$ & 0.03 & $0.18^{* * *}$ \\
\hline Occupational calling & & & $-0.19^{* * *}$ & & $-0.18^{* * *}$ \\
\hline COVID-19 pandemic disruption & & & & 0.01 & $0.07^{*}$ \\
\hline COVID-19 pandemic novelty & & & & $0.20^{* * *}$ & $-0.15^{* * *}$ \\
\hline COVID-19 pandemic criticality $\times$ disruption & & & & 0.04 & \\
\hline COVID-19 pandemic criticality $\times$ novelty & & & & $0.09^{*}$ & \\
\hline Occupational calling $\times$ COVID-19 pandemic disruption & & & & & -0.04 \\
\hline Occupational calling $\times$ COVID-19 pandemic novelty & & & & & -0.02 \\
\hline COVID-19 pandemic disruption $\times$ novelty & & & & -0.02 & $0.11^{* *}$ \\
\hline COVID-19 pandemic criticality $\times$ disruption $\times$ novelty & & & & $0.10^{*}$ & \\
\hline Occupational calling $\times$ COVID -19 pandemic disruption $\times$ novelty & & & & & $0.08^{*}$ \\
\hline$R$ & 0.26 & 0.40 & 0.31 & 0.46 & 0.37 \\
\hline$R^{2}$ & 0.07 & 0.16 & 0.10 & 0.21 & 0.13 \\
\hline$F$ & $12.34^{* * *}$ & $32.21^{* * *}$ & $15.46^{* * *}$ & $20.27^{* * *}$ & $10.83^{* * *}$ \\
\hline
\end{tabular}

${ }^{*} p<0.05,{ }^{* *} p<0.01,{ }^{* * *} p<0.001$. Standardized regression coefficients are reported

Fig. 3 Joint moderating effect of COVID-19 pandemic disruption and novelty on the link between COVID-19 pandemic criticality and occupational calling

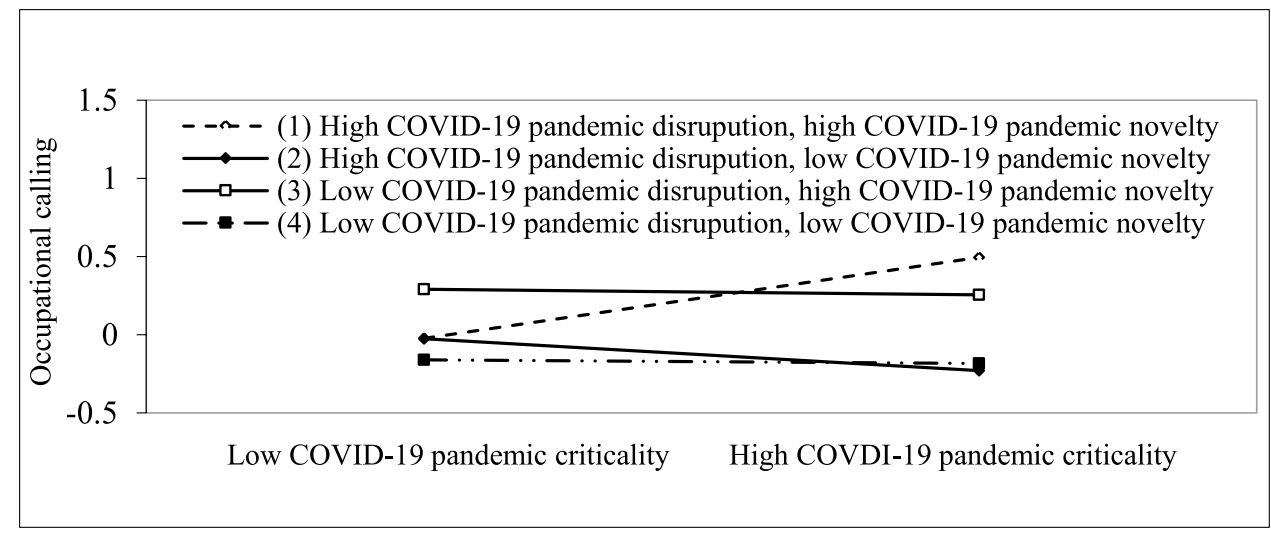

Table 4 The significance test of slope difference

\begin{tabular}{|c|c|c|c|c|c|c|c|}
\hline Path & Pair of slopes & $B$ & $t$ & Path & Pair of slopes & $B$ & $t$ \\
\hline \multirow{6}{*}{$\begin{array}{l}\text { COVID-19 pandemic criticality } \rightarrow \text { occupa- } \\
\text { tional calling }\end{array}$} & (1) vs (2) & 0.36 & $4.18^{* * *}$ & \multirow[t]{6}{*}{ Occupational calling $\rightarrow$ work fatigue } & (1) vs (2) & 0.12 & 1.42 \\
\hline & (1) vs (3) & 0.28 & $2.52^{*}$ & & (1) vs (3) & 0.08 & 0.09 \\
\hline & (1) vs (4) & 0.27 & $2.77^{* *}$ & & (1) vs (4) & -0.12 & $-1.30^{*}$ \\
\hline & (2) vs (3) & -0.09 & -0.77 & & (2) vs (3) & -0.04 & -0.41 \\
\hline & (2) vs (4) & -0.09 & -0.93 & & (2) vs (4) & -0.23 & $-2.75^{* *}$ \\
\hline & (3) vs (4) & -0.01 & -0.05 & & (3) vs (4) & -0.20 & $-2.11^{*}$ \\
\hline
\end{tabular}


Fig. 4 Joint moderating effect of COVID-19 pandemic disruption and novelty on the link between occupational calling and work fatigue

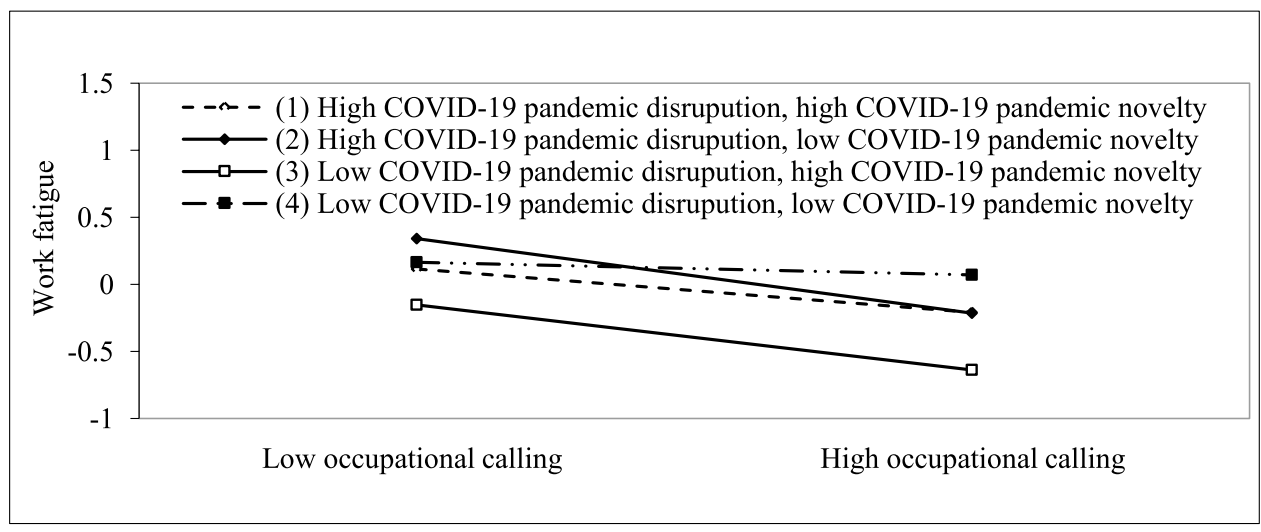

mediating effect was stronger under this condition, thus supporting Hypothesis 6.

\section{Discussion}

This study drew on EST to explore how COVID-19 pandemic strength attributes affect work fatigue among police officers in China. The results revealed that COVID-19 pandemic criticality positively influenced work fatigue through occupational calling. Moreover, COVID-19 pandemic disruption and novelty jointly moderated the first and second stages of the mediating effect. These findings make several theoretical and practical contributions to the literature.

\section{Theoretical Implications}

This study contributes to current research in three ways. First, our study is a practical application of EST to the COVID-19 pandemic global context. In addition, it increases our understanding of COVID-19 pandemic criticality and empirically accounts for the advantages and disadvantages of COVID-19 pandemic criticality among the police workforce based on EST. While the COVID-19 pandemic has garnered much attention, its attributes have been largely neglected in research (Caldas et al., 2021; Liu et al., 2020, 2021; Teng et al., 2020; Zhu et al., 2020). Our findings are consistent with some previous studies. Specifically, Zhu et al. (2021) found that the daily number of code blue events in the COVID-19 pandemic context was positively correlated with nurses' daily occupational calling, and COVID19 pandemic strength positively predicted perceived stress (Zhao et al., 2021), which resulted in job burnout (Y1ldırım \& Solmaz, 2020) and fatigue (Zhou et al., 2020). These findings enrich the empirical research base of EST and highlight the important influence of COVID-19 pandemic criticality on workplace outcomes among Chinese police officers.

Second, we investigated how COVID-19 pandemic criticality results in 13 by revealing the buffering role of occupational calling, which expands the literature on occupational calling in a collectivist culture. Although pandemic strength is an important factor in work stress (Burki, 2020; Khadse et al., 2020; Teng et al., 2020; Zhu et al., 2020) and fatigue (Liu et al., 2020; Zhou et al., 2020), insight into the underlying process of this association was limited. This study is the first to show the buffering effect of occupational calling on the link between COVID-19 pandemic criticality and work fatigue. This partially supports the findings of Zhou et al. (2020), who revealed that the correlation between police officers' occupational calling and work fatigue via role overload was U-shaped under the condition of high COVID19 pandemic disruption. Thus, our study expands extant research on the COVID-19 pandemic and work fatigue, and positively responds to the call to investigate the antecedents of occupational calling in different contexts and occupations

Table 5 The bootstrap test of the jointly moderated mediating effect

\begin{tabular}{|c|c|c|c|c|c|}
\hline \multirow[t]{2}{*}{ Model } & \multirow{2}{*}{$\begin{array}{l}\text { COVID-19 } \\
\text { pandemic } \\
\text { disruption }\end{array}$} & \multirow{2}{*}{$\begin{array}{l}\text { COVID-19 } \\
\text { pandemic } \\
\text { novelty }\end{array}$} & \multicolumn{3}{|c|}{ Indirect effect } \\
\hline & & & B & SE & $95 \% \mathrm{CI}$ \\
\hline \multirow[t]{4}{*}{ COVID-19 pandemic criticality $\rightarrow$ occupational calling $\rightarrow$ work fatigue } & Low & Low & -0.001 & 0.004 & {$[-0.008,0.010]$} \\
\hline & Low & High & 0.003 & 0.017 & {$[-0.038,0.033]$} \\
\hline & High & Low & 0.022 & 0.024 & {$[-0.020,0.075]$} \\
\hline & High & High & -0.036 & 0.021 & {$[-0.082,-0.002]$} \\
\hline
\end{tabular}


(Duffy et al., 2018; Lysova et al., 2018, 2019; Thompson \& Bunderson, 2019).

Third, this unique event-oriented research adds to a comprehensive understanding of the joint effect of the COVID19 pandemic strength attributes on workplace outcomes among police officers. Furthermore, it provides an integrative framework that identifies not only why COVID-19 pandemic criticality negatively affects work fatigue but also when this process is stronger. It has been acknowledged that the COVID-19 pandemic has caused emotional exhaustion and work fatigue in frontline workers. However, research has typically focused on one dimension of the pandemic. This study positively responded to the work of event researchers (Zhou et al., 2020), by examining the synergistic interactive impact of COVID-19 pandemic disruption and novelty on the link between COVID-19 pandemic criticality and work fatigue through occupational calling. This demonstrated that the synergistic impact of COVID-19 pandemic strength attributes played an important role in shaping police officers' occupational calling and work fatigue. Thus, we have revealed much about the joint impact of COVID-19 pandemic disruption and novelty. This provides a new and nuanced insight into the synergistic effect of the three attributes of COVID-19 pandemic strength on individuals' life and work outcomes.

\section{Practical Implications}

First, governments should focus more on the negative effects of the COVID-19 pandemic on police officers' work outcomes and provide social support from the organization and family. Currently, the pandemic is proliferating and becoming severe in some countries. In such situations, police officers are exposed to greater infection risk while on duty. Thus, more protective measures should be provided for these first responders. Leaders should appropriately mobilize work resources, assign tasks, and ensure adequate time off (Zhu et al., 2020). Furthermore, greater organizational and family support (Zhou et al., 2020), such as officer assistance programs, family relationship assistance (Stankovska et al., 2020; Teng et al., 2020), and psychological interventions could also help relieve fatigue.

Moreover, the positive impact of COVID-19 pandemic criticality on promoting occupational calling should also be considered. Studies indicate that occupational calling as a job-related resource is U-shaped and linked to police officers' work fatigue (Zhou et al., 2020). The dynamic and teachable characteristics of occupational calling (Dobrow, 2013; Duffy et al., 2014) also provide possibilities for training programs. Hence, police departments should be aware of the importance of promoting officers' occupational calling through training and education programs. Notably, however, our findings showed that occupational calling significantly relieved work fatigue only when COVID-19 pandemic disruption and novelty were either high or low. Accordingly, managers should recognize the different levels of occupational calling among officers.

\section{Limitations and Future Research}

This study has several limitations. First, the data were selfreported; hence, common method deviation was inevitable (Podsakoff et al., 2003). Multi-source data should be encouraged for future research, for example, occupational calling was rated by leaders or colleagues. Although a version of the 2 -item brief calling scale developed by Dik et al. (2012) had a high Cronbach's $\alpha$ in previous studies of Chinese participants at the beginning of the COVID-19 pandemic, it has potential statistical issues. Therefore, more versions with multiple items or dimensions of the occupational calling scale should be confirmed in the Chinese context. Second, although the selected model reflects the best fit among those we tested, the chi-square value of 5.43 is still larger than the commonly applied standard of 5.00 or less. However, other fit indices for the model are acceptable (noting that some researchers no longer rely on chi-square, because it is highly susceptible to manipulation via the sample size (Schermelleh-Engel et al., 2003). Third, according to EST (Morgeson et al., 2015), the COVID-19 pandemic development is dynamic; thus, the COVID-19 pandemic time, space, and strength could also affect police officers' work outcomes, respectively and jointly. However, our study only focused on the influence of pandemic strength attributes. Therefore, we suggest an explicit investigation of the link between pandemic time and space, as well as the synergetic interaction with strength attributes on the link between occupational calling and work fatigue. Finally, in this study, only the buffering role of occupational calling was examined. Future research should consider more potential mediators in the link between COVID-19 pandemic strength and work fatigue, such as job crafting (Vogt et al., 2016), which facilitates physical health and psychological well-being.

\section{Conclusion}

This study highlighted the important effect of COVID19 pandemic strength on police officers' workplace outcomes in the Chinese context, based on EST. It revealed that COVID-19 pandemic criticality positively affected work fatigue through occupational calling, and that the COVID-19 pandemic novelty and disruption had a joint moderating effect on this process. These results increase scholarly understanding of how and when pandemic criticality, novelty, and disruption impinge upon occupational calling and work fatigue. Furthermore, this study also 
provides suggestions for organizations, leaders, and families based on the findings. Finally, we hope that the study will provide new insights and implications for scholars and practitioners to tackle the challenges related to the pandemic.

Funding This work was supported by the General Project of Sichuan Social Security and Social Management Innovation Research Center of China under Grant [SCZA21A10], the Project of Sichuan Police Ideological and Political Research Center of China under Grant [CJS20B22], the Key Project of Luzhou Social Work and Health Management Research Center of China under Grant [SGJK202002], Soft Science Project of Science and Technology Department of Sichuan Province of China in 2022 under Grant [22RKX0611], and the National Natural Science Foundation of China under Grant [72074024].

Data Availability The data in this study are available on reasonable request to the corresponding author.

\section{Declarations}

Ethical Approval All procedures performed in studies involving human participants were in accordance with the ethical standards of the institutional and/or national research committee and with the 1964 Helsinki declaration and its later amendments or comparable ethical standards.

Consent to Participate All the participants provided their informed consent to participate in this study.

Conflict of Interest Not applicable.

\section{References}

Ashforth, B. E., \& Schinoff, B. S. (2016). Identity under construction: How individuals come to define themselves in organizations. The Annual Review of Organizational Psychology and Organizational Behavior, 3(1), 111-137. https://doi.org/10.1146/annurev-orgps ych-041015-062322

Bacharach, S. B., \& Bamberger, P. A. (2007). 9/11 and New York city firefighters' post hoc unit support and control climates: A context theory of the consequences of involvement in traumatic workrelated events. Academy of Management Journal, 50(4), 849-868. https://doi.org/10.5465/amj.2007.26279180

Beckers, D. G. J., Van der Linden, D., Smulders, P. G. W., Kompier, M. A. J., Taris, T. W., \& Geurts, S. A. E. (2008). Voluntary or involuntary? Control over overtime and rewards for overtime in relation to fatigue and work satisfaction. Work \& Stress, 22(1), 33-50. https://doi.org/10.1080/02678370801984927

Bullough, R. V., \& Hall-Kenyon, K. M. (2011). The call to teach and teacher hopefulness. Teacher Development, 15(2), 127-140. https://doi.org/10. 1080/13664530.2011.571488

Burke, R. J. (1994). Work-family stress, conflict, coping and burnout in police officers. Journal of Clinical Forensic Medicine, 1(1), 52. https://doi.org/10.1016/1353-1131(94)90068-x

Burki, T. (2020). Prisons are in no way equipped to deal with COVID19. Lancet, 395(10234), 1411-1412. https://doi.org/10.1016/ S0140-6736(20)30984-3

Caldas, M. P., Ostermeier, K., \& Cooper, D. (2021). When helping hurts: COVID-19 critical incident involvement and resource depletion in health care workers. Journal of Applied Psychology, 106(1), 29-47. https://doi.org/10.1037/apl0000850

Chen, Y., Liu, D., Tang, G., \& Hogan, T. M. (2021). Workplace events and employee creativity: A multi-study field investigation. Personnel Psychology, 74(1), 211-236. https://doi.org/10.1111/peps. 12399

Clinton, M. E., Conway, N., \& Sturges, J. (2017). "It's tough hangingup a call": The relationships between calling and work hours, psychological detachment, sleep quality, and morning vigor. Journal of Occupational Health Psychology, 22(1), 28-39. https://doi.org/ 10.1037/ocp0000025

Cooper, W. H., \& Withey, M. J. (2009). The strong situation hypothesis. Personality and Social Psychology Review, 13(1), 62-72. https://doi.org/10.1177/1088868308329378

Creed, P. A., Rogers, M. E., Praskova, A., \& Searle, J. (2014). Career calling as a personal resource moderator between environmental demands and burnout in Australian junior doctors. Journal of Career Development, 41(6), 547-561. https://doi.org/10.1177/ 0894845313520493

Deng, Y. X., \& Chen, X. P. (2019). Relationship between professional mission of grassroots police and job burnout: The regulating role of psychological disengagement. China Journal of Health Psychology, 27(9), 1394-139. https://doi.org/10.13342/j.cnki.cjhp. 2019.09.029

Dik, B. J., \& Duffy, R. D. (2009). Calling and vocation at work. The Counseling Psychologist, 37(3), 424-450. https://doi.org/10.1177/ 0011000008316430

Dik, B. J., Eldridge, B. M., Steger, M. F., \& Duffy, R. D. (2012). Development and validation of the Calling and Vocation Questionnaire (CVQ) and Brief Calling Scale (BCS). Journal of Career Assessment, 20(3), 242-263. https://doi.org/10.1177/1069072711434410

Dobrow, S. R. (2013). Dynamics of calling: A longitudinal study of musicians. Journal of Organizational Behavior, 34(4), 431-452. https://doi.org/10.1002/job.1808

Dobrow, S. R., \& Tosti-Kharas, J. (2011). Calling: The development of a scale measure. Personnel Psychology, 64(4), 1001-1049. https:// doi.org/10.1111/j.1744-6570.2011.01234.x

Drew, J. M., \& Martin, S. (2020). Mental health and well-being of police in a health pandemic: Critical issues for police leaders in a post-COVID-19 environment. Journal of Community Safety and Well-Being, 5(2), 31-36. https://doi.org/10.35502/jcswb.133

Duffy, R. D., Allan, B. A., Bott, E. M., \& Dik, B. J. (2014). Does the source of a calling matter? External summons, destiny, and perfect fit. Journal of Career Assessment, 22(4), 562-574. https://doi.org/ 10.1177/1069072713514812

Duffy, R. D., Bott, E. M., Allan, B. A., Torrey, C. L., \& Dik, B. J. (2012). Perceiving a calling, living a calling, and job satisfaction: Testing a moderated, multiple mediator model. Journal of Counseling Psychology, 59(1), 50-59. https://doi.org/10.1037/ a0026129

Duffy, R. D., Dik, B. J., Douglass, R. P., England, J. W., \& Velez, B. L. (2018). Work as a calling: A theoretical model. Journal of Counselling Psychology, 65(4), 423-439. https://doi.org/10.1037/ cou0000276

Eisenberger, R., Huntington, R., Hutchison, S., \& Sowa, D. (1986). Perceived organizational support. Journal of Applied Psychology, 71(3), 500-507. https://doi.org/10.1037/0021-9010.71.3.500

Frone, M. R., \& Tidwell, M. C. (2015). The meaning and measurement of work fatigue: Development and evaluation of the threedimensional work fatigue inventory (3D-WFI). Journal of Occupational Health Psychology, 20(3), 273-288. https://doi.org/10. 1037/a0038700

Fekedulegn, D., Burchfiel, C. M., Ma, C. C., Andrew, M. E., Hartley, T. A., Charles, L. E., et al. (2017). Fatigue and on-duty injury among police officers: The BCOPS study. Journal of Safety Research, 60, 43-51. https://doi.org/10.1016/j.jsr.2016.11.006 
Fornell, C., \& Larcker, D. F. (1981). Evaluating structural equation models with unobservable variables and measurement error. Journal of Marketing Research, 18(1), 39-50. https://doi.org/10.1177/ 002224378101800104

Gross, S., Semmer, N. K., Meier, L. L., Kälin, W., Jacobshagen, N., \& Tschan, F. (2011). The effect of positive events at work on after-work fatigue: They matter most in face of adversity. Journal of Applied Psychology, 96(3), 654-664. https://doi.org/10.1037/ a0022992

Haney-Loehlein, D. M., McKenna, R. B., Robie, C., Austin, K., \& Ecker, D. (2015). The power of perceived experience: Events that shape work as a calling. The Career Development Quarterly, 63(1), 16-30. https://doi.org/10.1002/j.2161-0045.2015.00092.x

Hayes, A. (2013). Introduction to mediation, moderation, and conditional process analysis. Journal of Educational Measurement, 51(3), 335-337. https://doi.org/10.1111/jedm.12050

Khadse, P. A., Gowda, G. S., Ganjekar, S., Desai, G., Murthy, P., Tripathi, S., et al. (2020). Mental health impact of COVID-19 on police personnel in India. Indian Journal of Psychological Medicine, 42(6), 580-582. https://doi.org/10.1177/0253717620963345

Lee, A. Y. P., Chen, I. H., \& Chang, P. C. (2018). Sense of calling in the workplace: The moderating effect of supportive organizational climate in Taiwanese organizations. Journal of Management \& Organization, 24(1), 129-144. https://doi.org/10.1017/jmo.2016. 16

Liu, D., Chen, Y., \& Li, N. (2021). Tackling the negative impact of COVID-19 on work engagement and taking charge: A multi-study investigation of frontline health workers. Journal of Applied Psychology, 106(2), 185-198. https://doi.org/10.1037/ap10000866

Liu, D., \& Liu, J. (2017). Dissecting event system theory: Tenets and opportunities for research and practice. Quarterly Journal of Management, 2(2), 64-80.

Liu, Y. Y., Zhang, Z. S., \& Zhao, H. (2020). The influence of the COVID-19 event on deviant workplace behavior taking Tianjin, Beijing and Hebei as an example. International Journal of Environmental Research and Public Health, 18(1), 59-75. https://doi. org/10.3390/ijerph18010059

Lysova, E. I., Dik, B., Duffy, R. D., Khapova, S. N., \& Arthur, M. B. (2019). Calling and careers: New insights and future directions. Journal of Vocational Behavior, 114, 1-6. https://doi.org/ 10.1016/j.jvb.2019.03.004

Lysova, E. I., Jansen, P. G., Khapova, S. N., Plomp, J., \& Tims, M. (2018). Examining calling as a double-edged sword for employability. Journal of Vocational Behavior, 104, 261-272. https://doi. org/10.1016/j.jvb.2017.11.006

Michaelson, C., \& Tosti-Kharas, J. (2019). Serving self or serving others? Close relations' perspectives on ethics and calling. Journal of Vocational Behavior, 114, 19-30. https://doi.org/10.1016/j.jvb. 2019.02.005

Mischel, W. (1977). The interaction of person and situation. In D. Magnusson \& N. S. Endler (Eds.), Personality at the crossroads: Current issues in interactional psychology (pp. 333352). Lawrence Erlbaum.

Morgeson, F. P., \& DeRue, D. S. (2006). Event criticality, urgency, and duration: Understanding how events disrupt teams and influence team leader intervention. The Leadership Quarterly, 17(3), 271-287. https://doi.org/10.1016/j.leaqua.2006.02.006

Morgeson, F. P., Mitchell, T. R., \& Liu, D. (2015). Event system theory: An event-oriented approach to the organizational sciences. Academy of Management Review, 40(4), 515-537. https://doi. org/10.5465/amr.2012.0099

Podsakoff, P. M., MacKenzie, S. B., Lee, J. Y., \& Podsakoff, N. P. (2003). Common method biases in behavioral research: A critical review of the literature and recommended remedies. Journal of Applied Psychology, 88(5), 879-903. https://doi.org/10.1037/ 0021-9010.88.5.879
Praskova, A., Creed, P. A., \& Hood, M. (2015). The development and initial validation of a career calling scale for emerging adults. Journal of Career Assessment, 23(1), 91-106. https://doi.org/ 10.1177/1069072714523089

Qiu, T., Yang, Y., Liu, C., Tian, F., Gu, Z., Yang, S., et al. (2020). The association between resilience, perceived organizational support and fatigue among Chinese doctors: A cross-sectional study. Journal of Affective Disorder, 265, 85-90. https://doi.org/ 10.1016/j.jad.2020.01.056

Ricci, J. A., Chee, E., Lorandeau, A. L., \& Berger, J. (2007). Fatigue in the U.S. workforce: Prevalence and implications for lost productive work time. Journal of Occupational and Environmental Medicine, 49(1), 1-10. https://doi.org/10.1097/01.jom.00002 49782.60321.2a

Rose, D. M., Seidler, A., Nübling, M., Latza, U., Brähler, E., Klein, E. M., et al. (2017). Associations of fatigue to work-related stress, mental and physical health in an employed community sample. BMC Psychiatry, 17(1), 1-8. https://doi.org/10.1186/ s12888-017-1237-y

Schermelleh-Engel, K., Moosbrugger, H., \& Müller, H. (2003). Evaluating the fit of structural equation models: Tests of significance and descriptive goodness-of-fit measures. Methods of Psychological Research, 8(2), 23-74.

Stankovska, G., Memedi, I., \& Dimitrovski, D. (2020). Coronavirus covid-19 disease, mental health and psychosocial support. Society Register, 4(2), 33-48. https://doi.org/10.14746/ sr.2020.4.2.03

Stogner, J., Miller, B. L., \& McLean, K. (2020). Police stress, mental health, and resiliency during the COVID-19 pandemic. American Journal of Criminal Justice, 41(4), 718-730. https://doi. org/10.1007/s12103-020-09548-y

Teng, Z. W., Wei, Z. R., Qiu, Y., Tan, Y. X., Chen, J. D., Tang, H., et al. (2020). Psychological status and fatigue of frontline staff two months after the COVID-19 pandemic outbreak in China: A cross-sectional study. Journal of Affective Disorder, 275, 247-252. https://doi.org/10.1016/j.jad.2020.06.032

Thompson, J. A., \& Bunderson, J. S. (2019). Research on work as a calling.... and how to make it matter. Annual Review of Organizational Psychology and Organizational Behavior, 6(1), 421443. https://doi.org/10.1146/annurev-orgpsych-012218-015140

Thorsteinsson, E. B., Brown, R. F., \& Richards, C. (2014). The relationship between work-stress, psychological stress and staff health and work outcomes in office workers. Psychology, 5(10), 1301-1311. https://doi.org/10.4236/psych.2014.510141

Trope, Y., \& Liberman, N. (2010). Construal-level theory of psychological distance. Psychological Review, 117(2), 440-463. https://doi.org/10.1037/a0018963

Vila, B. (2006). Impact of long work hours on police officers and the communities they serve. American Journal of Industrial Medicine, 49(11), 972-980. https://doi.org/10.1002/ajim.20333

Vogt, K., Hakanen, J. J., Brauchli, R., Jenny, G. J., \& Bauer, G. F. (2016). The consequences of job crafting: A three-wave study. European Journal of Work and Organizational Psychology, 25(3), 353-362. https://doi.org/10.1080/1359432X.2015.1072170

Word Health Organization. (2021). COVID-19 weekly epidemiological update. https://covid19.who.int/

Wright, T. A., \& Cropanzano, R. (2000). Psychological well-being and job satisfaction as predictors of job performance. Journal of Occupational Health Psychology, 5(1), 84-94. https://doi.org/10. 1037/1076-8998.5.1.84

Yang, C. J., \& Chen, A. B. (2020). The double-edged sword effects of career calling on occupational embeddedness: Mediating roles of work-family conflict and career adaptability. Asian Nursing Research, 14(5), 338-344. https://doi.org/10.1016/j.anr.2020.09. 005 
Y1ldırım, M., \& Solmaz, F. (2020). COVID-19 burnout, COVID-19 stress and resilience: Initial psychometric properties of COVID19 burnout scale. Death Studies. https://doi.org/10.13140/RG.2. 2.23216 .58883

Zhang, C. Y., Dik, B. J., Wei, J., \& Zhang, J. F. (2015). Work as a calling in China: A qualitative study of Chinese college students. Journal of Career Assessment, 23(2), 236-249. https://doi.org/10. $1177 / 1069072714535029$

Zhao, H., Xiong, J., Zhang, Z., \& Qi, C. (2021). Growth mindset and college students' learning engagement during the COVID-19 pandemic: A serial mediation model. Frontiers in Psychology, 12, 621094. https://doi.org/10.3389/fpsyg.2021.621094

Zhao, H. X., \& Zheng, X. M. (2013). Research on sense of calling at work: Current status and future directions. Economic Management, 35(10), 192-199. https://doi.org/10.19616/j.cnki.bmj.2013. 10.022

Zheng, J. H. (2020). "Watch" or "participate": The mediating effect of the attributes of COVID-19 between spatial distance and social participation. Journal of East China University of Science and Technology (social Science Edition), 35, 100-112.
Zhou, J., Zhang, J. W., \& Xuan, X. Y. (2020). The curvilinear relationship between career calling and work fatigue: A moderated mediating model. Frontiers in Psychology, 11, 583-604. https:// doi.org/10.3389/fpsyg.2020.583604

Zhu, X., Xia, M., Li, S., Hu, Y. Z., Zhang, L., Lu, Y., et al. (2020). Mental status and psychological needs of Chinese police officers in a highly impacted city during the COVID-19 pandemic. International Journal of Mental Health Promotion, 22(3), 149-157. https://doi.org/10.32604/IJMHP.2020.011097

Zhu, Y., Chen, T. T., Wang, J., Wang, M., Johnson, R. E., \& Jin, Y. H. (2021). How critical activities within COVID-19 intensive care units increase nurses' daily occupational calling. Journal of Applied Psychology, 106(1), 4-14. https://doi.org/10.1037/apl00 00853

Publisher's Note Springer Nature remains neutral with regard to jurisdictional claims in published maps and institutional affiliations. 